\title{
Ascetismo e inocência: a questão da religião no Humano, demasiado humano de Nietzsche
}

\author{
Jelson Roberto de Oliveira*
}

\begin{abstract}
Resumo: Pretende-se analisar, neste artigo, a estratégia histórico-fisiopsicológica utilizada por Nietzsche em Humano, demasiado humano no que diz respeito à sua análise da metafísica religiosa e, mais precisamente, do ascetismo. Para isso, demonstraremos como a argumentação nietzschiana chega à tese da inocência do ser humano e à demonstração de que o ascetismo e a santidade não passariam de um exercício de poder do indivíduo sobre si mesmo, como uma "ânsia de domínio" que, pela ausência de "objetos" externos, acaba se voltando contra si mesmo, pela via da "tiranização de partes de seu próprio ser", resultando no desprezo e no escárnio do homem consigo mesmo, sentimento que redunda na moralidade da culpa. $\mathrm{O}$ procedimento de Nietzsche, ao aliviar o homem desse peso, restabeleceria a inocência e a irresponsabilidade pela via da afirmação da necessidade de todas as coisas e da crítica à ideia de livre-arbítrio. Palavras-chaves: religião - Humano -Inocência - Ascetismo
\end{abstract}

Introdução

Humano, demasiado humano, publicado por Nietzsche em 1878, foi redigido a partir de 1876, logo após o rompimento com o projeto de renovação cultural representado pela arte wagneriana e apoiado na filosofia schopenhaueriana, ato que se consolidou com

* Professor do Programa de Pós-graduação em Filosofia da PUCPR, Curitiba, PR, Brasil. Email: jelsono@yahoo.com.br.

Cad. Nietzsche, São Paulo, n. 33, p. 215-244, 2013. I 215 
a decepção vivida durante a inauguração do Festival de Bayreuth, em agosto daquele ano (1876). A filosofia do espírito livre, produzida nesse período, não só representa o nascimento de uma "escola da suspeita" (MA I/HH I Prólogo 1, KSA 2.13) que passa a caracterizar a filosofia nietzschiana, mas é o símbolo da "grande liberação" (MA I/HH I Prólogo 3, KSA 2.16) vivida biograficamente por Nietzsche, o qual, depois da desilusão de Bayreuth, viaja com seus amigos Paul Rée e Albert Brenner (aos quais se junta, mais tarde, Malwida von Meysenburg) a Sorrento, um pequeno rincão no sul da Itália, onde os amigos fundam uma espécie de "claustro para espíritos livres" (KSB 5.188)1. Tal experiência, por sua importância teórica e biográfica, será decisiva para a elaboração das teses que serão apresentadas publicamente na obra de 1878.

O rompimento com o projeto musical de Wagner e com a filosofia de Schopenhauer, bem como a aproximação com as ideias de Paul Rée ${ }^{2}$, carrega consigo a formulação de duras críticas à filosofia metafísica, à arte romântica e à religião cristã, às quais Nietzsche contrapõe um novo modo de filosofar que ele denomina de "filosofia histórica" (MA I/HH I 1, KSA 2.23) e que não é outra coisa senão uma tentativa de aproximação entre a filosofia e a ciência, através de uma valorização das coisas humanas, demasiado humanas. A ciência, aí, deve ser entendida precisamente como interesse por tudo aquilo que configura, circunda e contém a existência humana, tais como a alimentação, moradia, vestuário, respiração, clima, relacionamentos

1 Sobre a importância dessa viagem de Nietzsche a Sorrento, cf. o livro do Prof. Paolo D'Iorio, Le voyage de Nietzsche à Sorrento. Genèse de la philosophie de l'esprit livre. (Paris: CNRS Éditions, 2012). Sobre a experiência da amizade (em especial com Paulo Rée) na formulação da filosofia de Nietzsche nesse período, entre outros trabalhos, cf. meu livro Para uma ética da amizade em Friedrich Nietzsche (Rio de Janeiro: 7Letras, 2011).

$2 \mathrm{Na}$ sua obra Nietzsche and Rée, Robin Small mostra como a amizade filosófica com Rée fora decisiva para a ruptura de Nietzsche com as ideias schopenhaurianas e wagneriadas, ao mesmo tempo em que fora fundamental para a formulação da sua própria filosofia, naquilo que Small chama de "queda no Réealismo" (2005, p. 111). Sobre esse assunto também pode ser consultada a introdução escrita por Small para a tradução inglesa dos Basic Writings de Paul Rée (2003, p. xi-liii). 
e fenômenos corporais etc. ${ }^{3}$ Tal modelo de ciência, assumido como "método científico" (MA I/HH I 635, KSA 2.360), passa a ser o modo de análise de tais coisas humanas, a fim de "impedir o triunfo da superstição e do contrassenso" (MA I/HH I 635, KSA 2.360) que medraram na cultura através dos idealismos metafísicos, os quais agora seriam confrontados com o "rigoroso método da verdade" (MA I/HH I 109, KSA 2.108) oferecido pela filosofia história, ou seja, aquela que, por contar a origem dos sentimentos morais, destitui a realidade das explicações metafísicas que, em todos os âmbitos, pretendem revelar a intervenção milagrosa de uma divindade.

Nesses termos, inegavelmente influenciado por Rée e seu "réealismus" (KSB 5.341) ${ }^{4}$, Nietzsche se utiliza da psicologia ${ }^{5}$ como modo de análise da origem dos sentimentos morais, acreditando

3 Num texto tardio, Nietzsche escreve mais diretamente sobre essa questão: "Perguntar-me-ão porque é que contei todas estas coisas pequenas e, segundo o juízo tradicional, indiferentes; causarei assim dano a mim próprio, e tanto mais quando estou destinado a representar grandes missões. Resposta: estas pequenas coisas [kleinen Dinge] - alimentação, lugar, clima, recreação, toda a casuística do egoísmo [die ganze Casuistik der Selbstsucht] - são muito mais importantes do que tudo quanto se concebeu e até agora se considerou importante. É aqui justamente que importa começar, aprende de novo. O que a humanidade até agora teve em séria consideração não são sequer realidades, são simples imaginações; em termos mais estritos, mentiras provenientes dos instintos maus de naturezas doentes, perniciosas no sentido mais profundo - todos os conceitos de 'Deus', 'alma', 'virtude', 'pecado', 'além', 'verdade', 'vida eterna'... Mas foi neles que se procurou a grandeza da natureza humana, a sua 'divindade'... Todas as questões da política, da organização social, da educação, foram de cima ao fundo totalmente falsificadas porque se tomaram como grandes homens os homens mais perniciosos - porque se ensinou a desprezar as coisas 'pequenas', ou seja, as preocupações fundamentais da vida... [...]. O necessário não é apenas para se suportar, menos ainda para se ocultar - todo o idealismo é mentira perante o necessário -, mas para o amar..." (EH, Por que sou tão sagaz, 10, , KSA 6.304).

4 Nessa carta enviada a Rée, datada de 10 de agosto de 1878, Nietzsche escreve: "Todos os meus amigos concordam que meu livro veio de você e foi mesmo escrito por você: logo, eu o congratulo por essa nova autoria (caso sua boa opinião não tenha mudado) (...) Vida longa ao Réealismo e ao meu bom amigo" (KSB 5.345). Em 24 de abril de 1878, Nietzsche já tinha escrito ao seu amigo, enviando um exemplar do seu novo livro: "Isto pertence a você, para os outros é somente dado" (KGB 5.324: Ihnen gehörts, - den Andern wird's geschenkt).

5 Sobre a relação de Nietzsche com a psicologia, além do texto do prof. Giacóia Júnior (Nietzsche como psicólogo), acompanhamos a interpretação proposta por Ruth Abbey no capítulo intitulado Nietzsche as Psychologist, em sua obra Nietzsche's Middle Period (2000, p. 17-33). Sobre a questão da fisiologia "como fio condutor" do pensamento, cf. RAMACCIOTTI, 2012, p. 65-90. 
com isso poder destituir a metafísica de seu lugar central na cultura ocidental, cuja história não é outra que a história de um erro que agravou o estado de adoecimento do homem. A psicologia é entendida, em sentido lato, como fisiopsicologia: a ciência que revela a história dos "sentimentos" que se originam psicofisiologicamente e necessitam de uma "arte da dissecação" (MA I/HH I 35, KSA 2.57). Nietzsche parte da constatação de que o "defeito de quase todas as filosofias é a falta de conhecimento do humano, uma análise psicológica inexata" (Nachlass/FP 1887, 22[107], KSA 8.365) e acredita nas "vantagens da observação psicológica" (MA I/HH I 35, KSA 2.57) como um meio que permite "aliviar o fardo da vida" (MA I/HH I 35, KSA 2.57). A análise científica, como dissecação histórico-fisio-psicológica é o experiente que, segundo Nietzsche, por desvendar os erros interpretativos ${ }^{6}$ em relação ao fenômeno humano, destituiriam as condições que tornaram a vida pesada. História e psicologia, passam a caracterizar, assim, "o duplo domínio metódico no interior do qual Nietzsche desenvolve sua crítica à moral"7

Assim, a psicologia de Nietzsche deve ser entendida como um instrumento ou mesmo como uma estratégia que se desenvolve em duas perspectivas: primeiro, ela é uma análise das coisas humanas e, segundo, uma análise da origem humana de todas as coisas (incluindo, aí, as metafísicas). Na primeira perspectiva, vemos a valorização daquilo que a tradição filosófica e moral emanada do modo metafísico de pensar tinha, segundo Nietzsche, tradicionalmente negligenciado e negado. Na segunda, a psicologia serviria

\footnotetext{
6 É importante notar que, ao denunciar os erros das interpretações metafísicas e mesmo buscar um método pretensamente mais "verdadeiro", Nietzsche não deixa de reconhecer que os erros são "necessários à vida" (MA I/HH I 33, KSA 2.52). Justamente ao falar do erro da metafísica, ele quer ressaltar o fato de que a metafísica nega a sua característica errática, ou seja, o fato de que ela é uma espécie de ilusão que, assim como acontece com a arte, também nasce de necessidades "ilógicas" (MA I/HH I 31, KSA 2.51) e "injustas" (MA I/HH I 32, KSA 2.51) que estão ligadas à vida. A filosofia histórica de Nietzsche seria mais verdadeira no sentido de que reconhece esse papel interpretativo e "errado" em si mesma.

7 Cf. TONGEREN, P.v., 2012, p. 86 e 87.
} 
de base para o resgate da procedência humana de todos os valores considerados pela tradição como advindos de seres e/ou mundos superiores, na forma de intervenções divinas ou mesmo de milagres. Nessa segunda possibilidade, a psicologia não é apenas e ciência das coisas humanas (como no primeiro caso), mas também uma história ${ }^{8}$ da procedência dos sentimentos morais que teriam no corpo a sua base primordial. Por isso, a filosofia de Nietzsche é um procedimento histórico-fisiopsicológico ${ }^{9}$ que se efetiva, em $\mathrm{Hu}$ mano, demasiado humano, como um projeto de crítica à metafísica.

Nesse sentido, o programa de Nietzsche inclui uma crítica à religião cristã implementada através de uma análise histórico-fisiopsicológica de sua procedência, tida como uma "necessidade metafísica" (MA I/HH I 26, KSA 2.47), a qual teria conseguido se impor a partir de uma reinterpretação da dor e do sofrimento como derivações de um castigo divino que se abatera sobre o homem, seja por sua "interpretação falsa" (MA I/HH I 126, KSA 2.122) a respeito de si mesmo (MA I/HH I 133, KSA 2.127), seja por sua beatificação, fazendo ver que o sofrimento de agora é critério para uma "felicidade eterna" (MA I/HH I 128, KSA 2.123).

Por uma filosofia da inocência: a má interpretação da dor como fundamento da religião

Mas como Nietzsche torne efetivo esse procedimento e qual é, de fato a sua eficácia no campo da análise religiosa? Ou, em outras palavras: como funciona tal "método" que propõe a restituir à vida e às coisas humanas a sua inocência? Para o interesse e o recorte teórico do presente artigo, usaremos como principal referência o capítulo de Humano, demasiado humano, intitulado

8 Sobre o conceito de história em Nietzsche, $c f$. ITAPARICA, 2005, p. 79-99.

9 Cf. RAMACCIOTTI, 2012, p. 65-90. 
A vida religiosa, mais exatamente os aforismos 124 a 144. Acreditamos que neles pode ser encontrado não só um exemplo do procedimento, tal como descrito acima, mas também, de alguma forma, o seu resultado principal, descrito por Nietzsche como um "alívio da existência” (MA I/HH I 36, KSA 2.58; 279, KSA 2.229; 280, KSA 2.230), um fruto maduro da "irresponsabilidade e da inocência" (MA I/HH I 105) que caracterizam a sua "filosofia da manhã" (MA I/HH I 638, KSA 2.363).

Nietzsche parte de uma convicção: que sua leitura "científica" da religião, ao desvendar os "erros da razão (MA I/HH I 124, KSA 2.121) que seriam seu fundamento, acabaria por purificar e inocentar o homem em relação à sua pretensa culpa através de uma leitura mais "verdadeira" da dor. Eis a questão central da análise de Nietzsche: a reinterpretação do sofrimento é apresentada como o móvel a partir do qual a religião teria ganhado espaço na cultura, ou seja, por ela oferecer uma "mudança da sensibilidade" (MA I/ HH I 108, KSA 2.107) quanto à dor. A religião teria sua base numa reinterpretação dos infortúnios (dores, sofrimentos, desgraças e infelicidades) que seriam parte dos desígnios divinos que, mesmo que sejam desconhecidos no presente, podem esconder intenções misteriosas que seriam aclaradas posteriormente. A religião pretende convencer o homem que ele não sofre à toa e que em todo sofrimento há um sentido que só seria conhecido posteriormente. Tal procedimento conduziria a um alívio momentâneo (eis o motivo do sucesso das religiões), ainda que não promovesse uma eliminação completa dos motivos da dor. Nietzsche acredita que essa é uma má incompreensão da dor (ou seja, a ideia de que ela deriva de uma vontade divina secreta, seja na linha da punição quanto de uma possível purificação nela contida), que reside o processo de adoecimento da cultura. Por isso, o seu método insiste tanto no desvendamento das origens, ou seja, das causas da dor, para demonstrar que todos os infortúnios são parte mesmo da existência e, com isso, eliminar a causa do sofrimento de maneira definitiva. 
Ao interpretar a dor como uma punição, a religião explica e legitima a ideia de pecado e também oferece a possibilidade da redenção: se sofre, é porque o homem é pecador; se e pecador, precisa implementar os expedientes ascéticos capazes de redimi-lo. A religião, assim, apenas pratica um dos modos de superação da dor: "modificando o efeito que produz em nossa sensibilidade" (MA I/ HH I 108, KSA 2.107). Obviamente, tal procedimento não é eficaz, segundo Nietzsche, sendo, ao contrário, responsável por um maior adoecimento do homem. Uma outra possibilidade, segundo o filósofo, seria "eliminando sua causa" (MA I/HH I 108, KSA 2.107). Esta é a perspectiva fisiopsicológica praticada por Nietzsche. Eliminar a causa, nesses termos, seria remontar a sua origem e desvendar a falsa interpretação religiosa que a sustenta.

Justamente por tal método a "ausência de pecado no homem" (MA I/HH I 124, KSA 2.121) passa a ser um resultado da compreensão a respeito da origem (no sentido da história) do surgimento do pecado tal como atrelado à falsa interpretação da dor. Isso explica a insistência de Nietzsche em fazer, do seu Humano, demasiado humano, um documento experimental da filosofia histórica nos termos de uma comparação entre o pecado e a inocência. Nas suas próprias palavras:

quando se compreende como 'o pecado chegou ao mundo', ou seja, através dos erros da razão, em virtude dos quais os homens entre si, e mesmo o indivíduo, se consideram muito mais negros e mais do que são de fato, então todo esse sentimento é muito aliviado, e os homens e o mundo aparecem por vezes numa aura de inocência (Unschuld) (MA I/ HH I 124, KSA 2.121).

Ao compreender o surgimento histórico-fisiopsicológico da religião, portanto, que envolve a necessidade metafísica como parte da tentativa de sanar a dor existencial, algo que se converteu na história de um erro a respeito da má-compreensão do homem e da natureza, Nietzsche pretende devolver o alívio e a inocência ao mundo. 
A figura evocada nesse aforismo 124 não é outra senão a da criança (imagem de grande importância na expressão da inocência do devir como inocência da natureza e do homem): eis o chamado "sol de um novo evangelho" que ilumina a história da origem do próprio pecado como um erro da razão, mostrando que, onde há culpa, é preciso reconhecer que "tudo é necessidade" e, consequentemente, que "tudo é inocência: e o conhecimento é a via para compreender essa inocência" (MA I/HH I 107, KSA 2.105).

A imagem religiosa de um "novo evangelho" expressa a verdadeira "cura" trazida por Nietzsche: a redenção da redenção, ou seja, a capacidade de reconhecer que todos os processos religiosos que propuseram a redenção e a superação da dor não passaram de erros e de fracassos que adoeceram ainda mais o homem. A verdadeira boa nova não pode ser outra senão aquela que fala de inocência, portanto, da capacidade de voltar a ser criança: o homem se reconhece em meio à natureza não mais como em meio à ação de seres superiores que o castigam arbitrariamente. Ao contrário: “em meio à natureza, o homem é sempre a criança" (MA I/HH I 124, KSA 2.121). Recuperada a inocência, o verdadeiro alívio aparece: não aquele que anula o sofrimento, mas aquele que não busca a culpa (ou o espírito de vingança) como causa do sofrimento: "esta criança tem às vezes um sonho pesado e angustiante, mas ao abrir os olhos está sempre de volta ao Paraíso" (MA I/HH I 124, KSA 2.121).

As dores da existência, portanto, não seriam mais reconhecidas como resultado da intervenção de seres superiores que vêm ao encontro do homem motivados pela ideia de castigo ou vingança, como diretores do destino humano. Agora, a natureza e a existência como um todo, até então interpretadas como resultado da ação de tais seres superiores ( $c f$. MA I/HH I 111, KSA 2.115) são novamente livres e inocentes. Por isso é possível ao homem, mesmo no meio da dor, "abrir os olhos" de novo e descobrir que está ainda no Paraíso, ou seja, no lugar da inocência.

Nietzsche identifica, no subsolo da interpretação da dor, portanto, o fundamento mesmo da religião ou, melhor ainda, da 
existência mesmo de Deus. O problema é que, ao inventar esse ser como perfeito, como "um ser que, sozinho, é capaz de todas as ações altruístas, e que vive numa contínua consciência de um modo de pensar desinteressado (...)" (MA I/HH I 132, KSA 2.125). Não apenas isso, como passa a se comparar a ele, algo que potencializa suas frustrações, pois a invenção de um tal ser, ao adquirir um caráter moral (o homem deve ser como Deus é ou deve agir conforme os seus desígnios), contribui para o sentimento de impotência, fraqueza e descontentamento do homem consigo mesmo, a tal ponto que ele sofra com sua própria condição. Para Nietzsche, portanto, esse ideal moral-religioso, embasado na invenção de um ser perfeito, é um dos principais fundamentos dos erros da razão promovidos pela metafísica religiosa.

Ao inverso dessa perspectiva, o procedimento da "filosofia científica" de Humano, demasiado humano, faria com que o homem se comparasse com os outros homens, evitando aquele equívoco primordial. "É porque olha nesse espelho claro que o seu ser lhe parece tão turvo, tão comumente deformado" (MA I/HH I 132, KSA 2.125): comparar-se a Deus (um ser perfeito) seria um dos motivos pelo qual o homem se sentiria diminuído e humilhado como ser imperfeito. Eis o quanto a imagem de um Deus perfeito pode prejudicar, frustrar e adoecer o ser humano. Mais do que isso: num segundo momento, o homem se sente mais angustiado, porque "o pensamento do mesmo ser, na medida em que este paira ante sua imaginação como a justiça punidora" (MA I/HH I 132, KSA 2.126) começa a importunar ainda mais a sua consciência. Deus passa a representar uma posição de violento assédio sobre o homem, o qual, "em todas as vivências possíveis, grandes ou pequenas, acredita reconhecer a cólera e as ameaças dele, e mesmo pressentir os golpes de açoite de seu juiz e carrasco" (MA I/HH I 132, KSA 2.126). A "duração imensurável da pena supera em atrocidade todos os outros terrores da imaginação" (MA I/HH I 132, KSA 2.126) e o homem passa a viver, literalmente, numa situação infernal sob a vigilância contínua da divindade. 
Essa situação à qual o homem está submetido não foi, entretanto, uma escolha sua, mas justamente um produto das falsas interpretações. O homem caiu nesse estado "por uma série de erros da razão" representados por Nietzsche na metáfora da "falha no espelho"10, segundo a qual o homem teria visto no espelho uma imagem distorcida de si mesmo, uma "natureza [que] lhe pareceu obscura e odiável" (MA I/HH I 133, KSA 2.127), sem se dar conta de que tal imagem é provocada por um espelho defeituoso. Em outras palavras: o que ele viu em si mesmo como feio e indesejável, seria apenas um resultado de uma distorção da projeção, ou seja, de uma falta interpretação. É essa "interpretação falsa, não científica" baseada em "erros" (MA I/HH I 134, KSA 2.128), que teria levado o cristão ao "estado de autodesprezo, de remorso, de desprazer" para consigo mesmo. Diante disso, a saída proposta por Nietzsche seria justamente um olhar mais "verdadeiro" nascido do procedimento científico que anula esses sentimentos e faz com que "tudo isso [seja] afastado de sua alma e ele se [sinta] livre e corajoso novamente" (MA I/HH I 134, KSA 2.129).

Nietzsche demonstra, através dessa argumentação, como, na religião, o homem vive um desgosto e um cansaço consigo; e como, justamente, pelo projeto expresso em Humano, demasiado humano, ele poderia retomar o prazer consigo, a leveza e a liberdade. Mas mesmo assim, a religião ainda não cede terreno: o cristão pode ainda, em alguns momentos, identificar em si mesmo um "raio da graça", pela qual passa a interpretar as suas vivências como resultado de uma "força externa". "O prazer consigo mesmo, o bem-estar com a própria força, aliados ao enfraquecimento necessário de toda emoção profunda, levaram a melhor" é associado a uma expressão divina. $\mathrm{O}$ amor com que ele ama a si mesmo passa a ser interpretado como uma forma do amor divino em relação a si mesmo.

10 Sobre essa temática cf. meu trabalho anterior intitulado Nietzsche e a falha do espelho ou sobre como interpretar também é inocentar (OLIVEIRA, 2012, p. 237-246). 
Por isso, contudo, não é ainda pelo procedimento científico que "o homem sente que de novo ama a si mesmo": mesmo aí sua "nova autoestima" (MA I/HH I 134, KSA 2.129) é interpretada como ação divina, fazendo com que aquilo que era interpretado como "avisos, ameaças, castigos e toda espécie de sinais da ira divina" agora contribua para que o homem passe a interpretar "suas experiências de modo a lhes introduzir a bondade divina" (MA I/HH I 134, KSA 2.129). A falsa interpretação que gerava aquele "estado de pesar" logo é substituída por uma interpretação que faz reconhecer o amor divino. Ou seja, o cristão continua preso às falsas interpretações, mesmo quando recupera o amor a si mesmo, porque sente que "aquilo que chama de graça e prelúdio de redenção é, na verdade, graça para consigo e redenção de si mesmo" (MA I/HH I 134, KSA 2.129). Para Nietzsche, portanto, a redenção do amor a si (hipótese radical, caso seja interpretada como uma implicação da filosofia científica), ainda, no caso cristão, permanece associada à interpretação de tipo religiosa.

Isso significa que o cristão continua atrelado à "psicologia falsa, certa espécie de fantasia na interpretação dos motivos e vivências" que, no fundo, seguem sendo o "pressuposto para que alguém se torne cristão e sinta necessidade de redenção" (MA I/ HH I 135, KSA 2.129). É essa "necessidade de redenção" que abastece o espírito religioso. Todavia, ela encontra seu nascimento numa "aberração do raciocínio e da imaginação" (MA I/HH I 135, KSA 2.129). Caso esse sentimento seja eliminado, "deixa-se de ser cristão" (MA I/HH I 135, KSA 2.129).

A religião como autodesprezo: uma análise psicológica do ascetismo

A partir do aforismo 136 até o final do capítulo reservado à Vida Religiosa, no 143, Nietzsche volta sua análise fisiopsicológica na direção do ascetismo e da santidade, o que o leva a confirmar, argumentativamente, as suas pretensões de inocentar as coisas 
Oliveira, J. R.

humanas, dado que elas teriam sido vítimas de "erros" e falsas interpretações. Vejamos como isso ocorre.

Para Nietzsche, ascetismo e santidade não são mais do que efeitos desses erros de avaliação a respeito da dor ou, ainda, das tentativas inadequadas de sua superação, interpretadas como algo inquestionável, como "coisa milagrosa, ante a qual seria quase sacrilégio e profanação manter o lume de uma explicação racional" (MA I/HH I 136, KSA 2.130). A má interpretação desses fenômenos pela via religiosa faz com que a ciência acabe por "levantar objeção à pretendida inexplicabilidade e mesmo inacessibilidade desses fenômenos" (MA I/HH I 136, KSA 2.130), expediente que não obteve sucesso, porque os religiosos e metafísicos geralmente preferem o inexplicável já que ele está quase sempre ligado ao "antinatural, sobrenatural, miraculoso" (MA I/HH I 136, KSA 2.130). Por isso há tanta resistência às explicações científicas desses fenômenos. A ascese e a santidade, entretanto, interpretadas pelo método científico, são tidas como de uma natureza "complexa" e "multiplamente condicionada". É preciso, nesse sentido, "isolar inicialmente alguns impulsos da alma dos santos e ascetas" (MA I/HH I 136, KSA 2.130) e realizar uma análise desses fenômenos, aparentemente complexos, a partir dos seus elementos mais simples.

No primeiro ponto dessa análise, Nietzsche demonstra - no aforismo 137 - que a ascese não passa de um exercício de poder sobre si mesmo por parte daqueles que "têm uma necessidade tão grande" de fazê-lo e alimentam uma "ânsia de domínio" cuja ausência de "outros objetos" acaba levando-os a recorrer "afinal à tiranização de partes de seu próprio ser", contra "segmentos ou estágios de si mesmos" (MA I/HH I 137, KSA 2.131). O "brilho" desse esforço, escolhido voluntariamente por pensadores e filósofos, faz com que diante dele "sua própria imagem pare[ça] terrivelmente feia" (MA I/HH I 137, KSA 2.131). Assim, a interpretação daquele despedaçamento de si mesmo, do "escárnio de sua própria natureza" e do desprezo geral consigo, "que as religiões deram tamanha importância, é na verdade um grau bastante elevado da 
vaidade" (MA I/HH I 137, KSA 2.131). O que Nietzsche sugere é que o homem tem "autêntica volúpia em se violentar por meio de exigências excessivas" e, sendo assim, toda forma de ascese não passaria de um tipo de exercício de poder contra si mesmo, uma manifestação da vontade de domínio e, em última instância, da vaidade de um ser que se volta contra si mesmo para mostrar o quão poderoso é. Trata-se de exercer esse poder para depois "endeusar em sua alma esse algo tirânico" que ele encontra em si mesmo. Por isso, segundo Nietzsche, "em toda moral ascética o homem venera uma parte de si como Deus, e para isso precisa demonizar a parte restante" contra a qual, a primeira se volta. A divisão do homem em um lado bom e outro mau esconde, portanto, a vaidade do asceta que quer exercer esse poder. Eis mais um resultado da análise fisiopsicológica.

Outro elemento destacado por Nietzsche tem a ver com a excitação emocional vivida pelos santos e ascetas. Segundo o filósofo, a elevação da emoção e a exaltação máxima da sensibilidade, provocadas pela religião, acabam levando o homem a encontrar no afeto a sua moralidade ("é no afeto que ele [o homem] é mais moral" [MA I/HH I 138, KSA 2.132]), já que a excitação emocional é capaz de levar o homem a "grandes decisões de sacrifício e abnegação". O método psicológico de Nietzsche, aplicado aos ideais religiosos, revela que "sob a influência da emoção violenta, ele quer de todo modo o que é grande, poderoso, monstruoso, e se por acaso ele nota que o sacrifício de si mesmo o satisfaz tanto ou ainda mais que o sacrifício do outro, escolhe aquele" (MA I/ HH I 138, KSA 2.132). Eis como o ascetismo é evocado: como possibilidade de "descarga de sua emoção", ou seja, voltando-se contra si mesmo, o homem busca um alívio de suas emoções: "para aliviar sua tensão, pode juntar as lanças dos inimigos e enterrá-las no próprio peito" (MA I/HH I 138, KSA 2.132). É aí, justamente, na "negação de si mesmo", que o asceta encontra a sua grandeza e seu símbolo maior é justamente "uma divindade que sacrifica a si mesma". Esse foi o "símbolo mais forte e mais eficaz dessa espécie 
de grandeza" que o asceta também encontra em si mesmo através dos processos de repressão que institui contra si. Por isso, o "ápice da moral" não seria outra coisa do que "a vitória do inimigo mais difícil de vencer", ou seja, a vitória sobre os próprios afetos, sua “dominação repetida" (MA I/HH I 138, KSA 2.132). O olhar do outro, que também experimentou a dificuldade dessa tarefa, e sua admiração, sustentam a atitude de abnegação, fazendo com que a vaidade prevaleça e o "orgulho [seja] seu consolo" (MA I/HH I 138, KSA 2.132). A abnegação de si, como tarefa moral, esconderia, assim, um elemento não moral, a vaidade.

A análise de Nietzsche evidencia ainda um terceiro elemento: a submissão à tutela de uma vontade alheia. Para o filósofo, o asceta também tentaria "tornar leve a sua vida" (MA I/HH I 139, KSA 2.133) e para isso, uma das medidas é, segundo Nietzsche, a "completa subordinação a uma vontade alheia, ou a uma lei e um ritual abrangentes", fazendo-se guiar por preceitos exteriores, no geral tidos por sagrados. Obedecendo ao que o outro lhe exige, o indivíduo se livra de qualquer "sentimento de responsabilidade" ou da "tortura do arrependimento" (MA I/HH I 139, KSA 2.133), porque, no fundo, não foi ele quem escolheu fazer, mas um outro fora de si. Por isso a "renúncia da vontade" aparece como um ato relevante do ponto de vista religioso: é mais "cômodo": santos e ascetas "facilita[m] a própria vida pelo completo abandono da personalidade" (MA I/HH I 139, KSA 2.133). Interpretado com as ferramentas propostas por Nietzsche, esse processo acabaria revelando que seria "um engano admirar nesse fenômeno o supremo valor da moralidade" (MA I/HH I 139, KSA 2.133), já que, em todo caso, é bem "mais difícil afirmar a personalidade sem hesitação e sem obscuridade do que dela se libertar" (MA I/HH I 139, KSA 2.133). Ou seja, o caminho do asceta (de abnegação de si) é muito mais fácil do que o daqueles que buscam a afirmação de si, pois este "requer muito mais espírito e reflexão".

Nietzsche está, com toda essa argumentação, tentando mostrar que é possível encontrar "em muitas das ações mais difíceis 
de explicar, expressões daquele prazer na emoção em si" (MA I/ HH I 140, KSA 2.133). Mas esse não é o único elemento: é preciso "reconhecer também no autodesprezo, que se inclui entre as características da santidade, e igualmente nos atos de tortura de si mesmo (jejum e açoitamento, deslocação dos membros, simulação da loucura), um meio pelo qual essas naturezas lutam contra a fadiga geral de sua vontade de viver (de seus nervos)" (MA I/HH I 140, KSA 2.134). Para Nietzsche o autodesprezo e as medidas que lhe acompanham "servem de estímulos" (MA I/HH I 140, KSA 2.134) para que as almas possam, "ao menos temporariamente, emergir do torpor e do tédio em que uma grande indolência espiritual e a mencionada subordinação a uma vontade alheia as fazem cair com tanta frequência" (MA I/HH I 140, KSA 2.134). É para fugir do tédio, do vazio e da monotonia ( $c f$. MA I/HH I 115, KSA 2.118) que os homens religiosos dirigem contra si mesmos tantos expedientes punitivos.

O "inimigo interior" (MA I/HH I 141, KSA 2.134) que o santo e $o$ asceta carregam em si mesmos serve, portanto, de estímulo para que a sua vida seja ainda "suportável e interessante", pois ele precisa, para isso, permanecer numa "guerra ocasional e na alternância da vitória e derrota" (MA I/HH I 141, KSA 2.134). Por isso, identifica em si mesmo, em sua "tendência à vaidade, a sede de glória e domínio, e também seus apetites sensuais" móveis contra os quais deve implementar essa batalha. Para manter essa guerra constante que lhe traz algum interesse pela vida, o santo e o asceta tornariam a sua "vida uma contínua batalha e a si mesmo[s] um campo de batalha" (MA I/HH I 141, KSA 2.134).

A fantasia sensual seria um bom exemplo desse expediente, pois ela acaba, segundo Nietzsche, sempre sendo fortalecida pela privação: quando mais é reprimida, mais se tornaria "desenfreada e dissoluta" (MA I/HH I 141, KSA 2.134). A guerra contra os apetites lhe serviria de estímulo, portanto. Isso explicaria, segundo Nietzsche, porque as fantasias "de muitos santos cristãos foi incomumente obscena", mas como eram interpretadas como "verdadeiros demônios que lhes assolavam o íntimo" então eram facilmente 
classificadas no âmbito daquilo sobre o qual esses indivíduos não eram responsáveis. Tratava-se de um constante entretimento para suas vidas desgostosas e tediosas. Quanto mais "difamada e estigmatizada" a sensualidade, sob o "perigo de uma danação eterna" (MA I/HH I 141, KSA 2.134), mais os religiosos angariavam adeptos para suas teorias, sobre os quais podem emitir suas sanções. Para Nietzsche, o ato da procriação foi recoberto de uma vergonha e de uma difamação, de tal forma a fazer com que muitos filhos fossem gerados como produtos de um pecado. Por isso, segundo o filósofo, "em todas as religiões pessimistas, o ato da procriação é experimentado como ruim em si” (MA I/HH I 141, KSA 2.135). No cristianismo, entretanto, esse não era o maior interesse: "no deserto espiritual de suas vidas precisavam de um inimigo sempre vivo" e por isso, acabaram perseguindo a sensualidade para que todos alimentassem certo desejo de também se tornarem maus, pelo menos para terem contra quem lutar: "as pessoas queriam se achar tão más e perversas quanto possível" (MA I/HH I 141, KSA 2.135).

Ocorre que a análise psicológica, segundo Nietzsche, acaba por concluir que quando aquilo que é natural e humano passa a ser considerado moralmente mau, faz com que os homens se tornem "piores". Eis a astúcia religiosa: "é o artifício da religião, e dos metafísicos que querem o homem mau e pecador por natureza, suspeitar-lhe a natureza e assim torná-lo ele mesmo ruim" (MA I/ HH I 141, KSA 2.135). Não podendo se “despir do hábito da natureza" o homem vai aprendendo, aos poucos, a se considerar mau de fato. Aos poucos, sugere Nietzsche, "no curso de uma longa vida no interior do natural, dele se sente tão oprimido por esse fardo de pecados, que são necessários poderes sobrenaturais para lhe tirar esse fardo": a religião encontra um mecanismo de retroalimentação, portanto, e o alívio da existência passa a requer uma força extrassensível, metafísica. Com isso, sua "necessidade de redenção" (MA I/ HH I 141, KSA 2.135) ganharia novo fôlego. O artifício, aqui, seria exagerar tanto nas exigências morais, que elas se tornassem inalcançáveis: "examinando uma a uma as teses morais dos documentos 
do cristianismo, veremos que os requisitos são exagerados, de modo que o homem não possa satisfazê-los" (MA I/HH I 141, KSA 2.136). Por isso, o procedimento científico utilizado por Nietzsche chegaria ao questionamento máximo do sentido da própria moral: “a intenção não é que ele se torne mais moral, mas que se sinta o mais possível pecador" (MA I/HH I 141, KSA 2.137), para assim, se tornar ainda mais dependente das medidas morais oferecidas da religião.

Trata-se de um sentimento "agradável" de autodesprezo, que dá um sentido contrário à moral, na medida em que inverte o seu propósito, com o fim de estimular o homem, não no sentido grego, que investiu "incomensurável força de espírito e engenho para aumentar a alegria de viver mediante cultos festivos" (MA I/HH I 141, KSA 2.137), mas no sentido cristão, aquele que quer o homem como pecador para, no fim, com isso, fazer com que ele seja "estimulado, vivificado, animado" (MA I/HH I 141, KSA 2.137). Ora, pergunta Nietzsche, essa não é "uma divisa de uma época amolecida, demasiado madura e cultivada?" (MA I/HH I 141, KSA 2.137). Santos e ascetas inventaram, assim, um "novo gênero de estímulos para a vida" num tempo de pobreza e esvaziamento. Sua exposição, aos olhos dos demais, era um espetáculo horroroso que encantava os expectadores e garantia-lhes uma espécie de prazer.

Nietzsche propõe, no aforismo 142, um resumo de sua argumentação, afirmando que "aquele estado de alma de que goza o santo ou o aspirante à santidade" (MA I/HH I 142, KSA 2.138) é bem conhecido de todos, mas que, "sob a influência de certas ideias religiosas" acabam aparecendo em "cores diversas", para que contem com o apoio dos homens, quando, caso fossem apresentadas racionalmente, pudessem contar com sua reprovação.

Essa apresentação do santo não através do que ele de fato é, mas do que ele "significa aos olhos dos não-santos" (MA I/HH I 143, KSA 2.139) é o que fez com que tal personagem moral alcançasse "a força extraordinária com que pode dominar a imaginação de povos e épocas inteiras" (MA I/HH I 143, KSA 2.139). Algo que nem ele mesmo conhecia de si mesmo parece se revelar: 
“o excêntrico e doentio de sua natureza, com sua junção de pobreza espiritual, saber precário, saúde arruinada, nervos superexcitados, permanecia oculto tanto a seu olhar como ao de seu espectador" (MA I/HH I 143, KSA 2.139). Ele não era nem bom e nem sábio, mas significava algo de um nível extra-humano que fazia com que "a crença nele sustentava a crença no divino e miraculoso" (MA I/ HH I 143, KSA 2.139).

Eis o poder do santo, cujas atitudes seriam de quatro tipos: [1] ele "pratica o desafio de si mesmo, que é um parente próximo da ânsia de domínio" que lhe faz voltar sempre sobre si mesmo (aforismo 137); [2] "seu sentimento inflado salta do desejo de dar rédea livre a suas paixões" para que, afinal, rendam-se "sob a pressão potente de uma alma orgulhosa" (aforismo 138); [3] "deseja uma cessação completa de todos os sentimentos que o perturbam, torturam ou excitam" (aforismo 139); [4] "procura a luta e a desperta em si mesmo, porque o tédio lhe mostra o seu rosto bocejante" (aforismos 140 e 141).

O resultado, em termos humanos, desse procedimento religioso é descrito por Nietzsche nas seguintes palavras:

Ele flagela seu auto-endeusamento com autodesprezo e crueldade, se alegra com o selvagem tumulto de seus apetites, com a dor aguda do pecado e mesmo com a ideia da perdição, sabe armar ciladas para o seu afeto, para o extremo anseio de domínio, por exemplo, de modo que ele passe a extrema humildade, e sua alma atiçada é subvertida por esse contraste; por fim, quando anseia por visões, diálogos com os mortos e seres divinos, o que no fundo deseja é uma espécie rara de volúpia, talvez aquela volúpia na qual todas as outras se acham atadas como num feixe. (MA I/HH I 142, KSA 2.138).

O que o filósofo está propondo é uma interpretação científica daqueles processos e vivências que foram mal interpretadas pelo cristianismo. $\mathrm{O}$ que faz da nova interpretação de Nietzsche, mais verdadeira do que a antiga, é o critério do quanto a visão cristã 
levou não para um enfrentamento da dor humana, mas para um maior adoecimento do homem. Nietzsche, no fundo, acredita que, com sua análise, conseguirá de fato aliviar a vida pela via da inocência do homem ${ }^{11}$.

Nietzsche, entretanto, não encerra a sua reflexão sem falar de exceções: "há exceções que se destacam na espécie", escreve ele no aforismo 144, o último desse capítulo, "seja por sua imensa brandura e simpatia com os homens, seja pelo encanto de uma energia incomum". "É o caso do célebre fundador do cristianismo, que acreditava ser filho de Deus e portanto isento de pecado", exemplo de uma atração de "altíssimo grau". Jesus seria o exemplo de um santo que, através de uma ilusão (a de que era um filho de Deus, como tantos outros na Antiguidade), "alcançou o mesmo objetivo, o sentimento de completa isenção de pecado, da plena irresponsabilidade, que hoje qualquer homem pode adquirir através da ciência" (MA I/HH I 144, KSA 2.140). Mesmo os santos hindus representariam uma possibilidade de "elevação acima dos demais homens pela disciplina e educação lógica do pensamento" (MA I/ HH I 144, KSA 2.140). Essas últimas linhas parecem evocar o fato de que, ao resumir e simplificar sua reflexão sobre a vida religiosa, Nietzsche tenha usado como critério justamente aquele da afirmação da vida no sentido de uma integralidade entre o sofrimento. Ao contrário das más-interpretações da religião no seu conjunto, tanto

11 Sobre o tema do alívio da existência, o qual será melhor discutido mais abaixo, cf. a obra de Olivier Ponton, Nietzsche - Philosophie de la légèreté (2007), que pretende demonstrar como o tema da leveza é um ponto central da filosofia nietzschiana, principalmente a partir das obras do segundo período, nas quais se identifica uma tentativa de pensar uma moral de "alívio da vida" ou ainda, "uma moral que se apoia sobre uma filosofia da leveza" (p. 1). A leveza seria, segundo Ponton, não uma ausência de peso, mas uma capacidade de suportar o peso, uma força ativa e voluntária que estabelece a pretensão não de aliviar $d a$ vida, mas de aliviar $a$ vida. Essa discussão está de acordo com nossa interpretação, segundo a qual as dores e sofrimentos, para as quais a metafísica oferece um alívio na forma de narcoses (a religião é uma dessas "artes da narcose" [MA I/HH I 109, KSA 2.108]) que tentam retirar o "peso" da vida, ao invés de favorecerem a força para o seu enfrentamento. 
Jesus (pela via da ilusão) quanto os hindus (pela via da educação lógica do pensamento) teriam conquistado uma verdade mais efetiva, destituída daqueles atributos de abnegação de si, tão fortemente evocados nos ambientes religiosos.

\section{Irresponsabilidade e inocência}

Voltemos à questão da inocência, que é o eixo temático central desse trabalho. Comecemos nos perguntando, com Nietzsche, se o interesse pelas coisas humanas não tornaria a vida e a própria filosofia "pesada" demais? Não teria esse esforço de conhecimento transformado a filosofia numa "tragédia" (MA I/HH I 34, KSA 2.53)? Se o conhecimento "só pode admitir como motivos o prazer e o desprazer, o proveitoso e o nocivo" então como ainda poderíamos ligá-lo ao "senso de verdade" (MA I/HH I 34, KSA 2.53)? Não seria necessário - como se fez historicamente - deixá-lo no erro, sob o benefício de ser prazeroso? Sendo assim, "restaria apenas um modo de pensar que traz o desespero como conclusão pessoal e uma filosofia da destruição como conclusão teórica" (MA I/HH I 34, KSA 2.54)? Nietzsche sabe que seu procedimento é custoso e pode levar a irritações com o passado sobre o qual só o "temperamento de um homem poderá decidir quanto ao efeito posterior do conhecimento" (MA I/HH I 34, KSA 2.54). Para ele, esse "temperamento" decidirá sobre como agir frente às novas verdades (que nada mais são do que a conclusão de que "a vida humana está profundamente embebida na inverdade" [MA I/HH I 34, KSA 2.54]). Há quem prefira o prazer do conhecimento e recue para o terreno da metafísica, há "naturezas individuais" que buscariam "uma vida mais simples e mais pura de paixões" e que encontrariam um "conhecimento purificador" que paulatinamente venceria o medo da vida: "afinal se viveria, entre os homens e consigo, tal como na natureza, sem louvor, censura ou exaltação, deleitando-se com muitas coisas, como um espetáculo do qual até então se tinha apenas medo" 
(MA I/HH I 34, KSA 2.54). Essa espécie de "naturalização da moral", pela via de uma entrega à natureza terá, como se sabe, repercussões decisivas em obras posteriores, como Além de bem e mal e a própria Genealogia, mas o interesse pelas coisas humanas e mundanas já está presente em Humano, demasiado humano, no qual Nietzsche realiza a "atividade de um naturalista" na medida em que trata de não ignorar mais que "o homem está inserido em um mundo natural" 12 . Ou seja, a integração do homem, suas ações e interpretações, ao mundo da natureza, enquanto hipótese procedimental, é um dos pontos chaves para a análise do fenômeno religioso, bem como de toda a crítica de Nietzsche à metafísica já a partir de Humano, demasiado humano.

Saber que é "apenas natureza" é o resultado do procedimento histórico-fisiopsicológico que revela tudo como "necessidade" e não mais como livre-arbítrio ${ }^{13}$. $\mathrm{O}$ antídoto de Nietzsche à velha concepção de liberdade é a de uma grande liberdade, aquela que é uma liberdade diante do livre-arbítrio, que entendia as ações humanas como parte do jogo de escolhas que o submetia à culpa e à responsabilidade. Esse raciocínio não passaria, para Nietzsche, de uma "fábula" (MA I/HH I 39, KSA 2.62) que transcorre como uma sucessão de erros: "sucessivamente tornamos o homem responsável por seus efeitos, depois por suas ações, depois por seus motivos e finalmente por seu próprio ser" (MA I/HH I 39, KSA 2.62). Mas Nietzsche chega a um quinto ato dessa história, aquela que revela que "não se pode tornar o homem responsável por nada"

12 ITAPARICA, 2008, p. 32.

130 tema do livre-arbítrio é um dos mais frequentes na filosofia de Nietzsche: já em 1865 ele escreve o texto Liberdade da vontade e fato (sob influência de suas leituras de Ralph Waldo Emerson e no qual o fato é apresentado como necessário e não livre e a luta contra ele um processo de fortalecimento individual); no segundo período o tema aparece de forma constante, já que fazia parte dos interesses de Paul Rée, que escrevera sobre o assunto; o tema retorna em obras como Além de Bem e Mal, Assim Falou Zaratustra e Crepúsculo dos Ídolos (principalmente no capítulo sobre $O s$ "melhoradores" da humanidade). Trata-se de um dos temas fundamentais da ética da compaixão, tratado por Schopenhauer, principalmente, no livro quarto de $O$ Mundo como vontade e como representação (especialmente no $§ 70$ ). 
porque todas as coisas humanas são "consequência necessária e se forma[m] a partir dos elementos e influxos de coisas passadas e presentes" (MA I/HH I 39, KSA 2.63). Tudo é necessidade, significa que tudo é jogo de acaso e da falta de finalidade:

Então há apenas um reino, o dos acasos e da estupidez?" - devemos acrescentar: sim, talvez haja somente um reino, talvez não exista vontade nem finalidade, e nós apenas as imaginamos. As mãos férreas da necessidade, que agitam o copo de dados do acaso, prosseguem jogando por um tempo infinito: têm de surgir lances que semelham inteiramente a adequação aos fins e a racionalidade (M/A 130, KSA 2.123).

O que Nietzsche pretende demonstrar é que a vida não é guiada por finalidades e, consequentemente, que o homem não é detentor de uma capacidade superior de escolha. Todas as interpretações de mundo (portanto, também as morais) são derivadas das necessidades. É o que se lê num fragmento póstumo do período tardio, que evocamos aqui por sua eficiência argumentativa: "São as nossas necessidades que interpretam o mundo: os nossos instintos, os seus prós e os seus contras. Cada instinto é uma espécie de despotismo, cada um tem a sua perspectiva, que gostaria de impor como norma aos restantes instintos" (Nachlass/FP 1886-1887, 7[60], KSA 12.315). Falar em necessidade, na linguagem desse período, é falar de instintos, impulsos e pulsões geradores de interpretações de mundo. Eis o que torna o mundo e todas as suas interpretações (incluindo os chamados "erros" da metafísica), um resultado das necessidades humanas, um produto delas:

Todo esse mundo que realmente nos importa, no qual estão enraizados nossas necessidades, nossos desejos, nossas alegrias, nossas esperanças, nossas cores, nossas linhas, nossas fantasias, nossas orações e nossas maldições - todo esse mundo foi criado por nós homens, e nos esquecemos disso, de modo que posteriormente inventamos um criador próprio para tudo. Assim como a linguagem é o poema originário de 
um povo, o mundo inteiro, sentido intuitivamente, é a poesia originária da humanidade, e já os animais começaram a compô-la. Isso nós herdamos de uma só vez, como se fosse a própria realidade (Nachlass/FP 1881, 14[8], KSA 9.624).

Como "poesia originária" o mundo é interpretação ilusória e errática produzida pelo ser humano, algo que é cumulativo do ponto de vista histórico e herdado pelos homens do presente. O problema da metafísica é que ela "esquece" disso e acaba inventando patamares superiores a partir dos quais tudo seria "criado". Falar, portanto, em necessidade, é reconhecer que tudo foi criado como modo de vida - e somente isso.

Por isso, no aforismo 39 de Humano, demasiado humano, Nietzsche anuncia um novo conhecimento, o conhecimento do desconhecimento, o conhecimento da inverdade como parte da vida, o conhecimento da história de um erro que se quis verdade quando a verdade, ela mesma, não pode ser uma coisa retirada do mundo, um produto de uma realidade outra, superior: "Com isso chegamos ao conhecimento de que a história dos sentimentos morais é a história de um erro, o erro da responsabilidade, que se baseia no erro do livre-arbítrio" (MA I/HH I 39, KSA 2.63). Criticando diretamente Schopenhauer, Nietzsche afirma que o erro fundamental do livre-arbítrio é entender que "o homem se torna o que ele quer ser, seu querer precede sua existência" (MA I/HH I 34, KSA 2.63). Ora, para Nietzsche o homem é um existente fazendo a si mesmo a partir das necessidades vitais e teria sido justamente o livre-arbítrio um atributo mentiroso que levou ao adoecimento do homem: "porque se considera livre, não porque é livre, ele sofre arrependimento e remorso" (MA I/HH I 39, KSA 2.64). Nesse caso, o homem não é livre: consequência dessa afirmação teria levado a filosofia metafísica ao terreno da "sombra e da inverdade", ou seja, teria feito como que seus arautos preferissem o deleite das explicações totais, pretensamente puras e verdadeiras. Isso por "medo das consequências", ou seja, por medo de terem de reconhecer que 
suas próprias construções são parte de um erro e mesmo que suas narcoses eram dispensáveis, pois o homem, sendo necessário, é também irresponsável e inocente.

Não é à toa que Nietzsche encerra o capítulo intitulado Contribuição à história dos sentimentos morais com um aforismo cujo título é Irresponsabilidade e inocência: de fato, a inocência é a última página (a página escrita por Nietzsche) da história da moral, aquela que desvela o quanto de erro esteve escondido sob as construções da verdade absoluta pregada pela metafísica. Contudo, o tom dessa nova página não é de prazer e alegria ingênuos: "a total irresponsabilidade do homem por seus atos e seu ser é a gota mais amarga que o homem do conhecimento tem de engolir" (MA I/HH I 107, KSA 2.103) porque precisa abrir mão da "carta de nobreza de sua humanidade" que lhe era conferida, tradicionalmente, pela ideia de livre-arbítrio e de responsabilidade. O resultado desse procedimento é que "todas as suas avaliações, distinções, aversões, são assim desvalorizadas e se tornam falsas" porque não se pode mais nem "louvar" e nem "censurar" a natureza e a necessidade. Todos os atos humanos e seus próprios atos exigem agora a atitude de alguém que se coloca diante da natureza: resta "admirar a força, a beleza, a plenitude, mas não lhes pode achar nenhum mérito" (MA I/HH I 107, KSA 2.103). Para Nietzsche, todos os motivos das ações "brotaram das mesmas raízes que acreditamos conter os mais venenos", as raízes humanas, demasiado humanas das necessidades. Tudo, nesse campo das ações, estaria submetido a uma única lógica: a auto-fruição do indivíduo, diante do que, o que é considerado bom aparece apenas como uma variação de grau em relação ao que é considerado mau. Prova disso é a mudança entre indivíduos e sociedades no tempo e no espaço em relação ao que é o bom e o mau: como depende de suas necessidades, há diversificados interesses em suas projeções.

Nietzsche está ciente de que "compreender tudo isso pode causar dores profundas, mas depois há um consolo: elas são as dores do parto" (MA I/HH I 107, KSA 2.105), ou seja, a partir 
desse nascimento, reinará a luz da plena liberdade, aquela que pode mesmo cegar ou confundir a borboleta que acaba de romper o seu casulo ( $c f$. MA I/HH I 107, KSA 2.105). Trata-se da efetivação daquela "grande liberação" (MA I/HH I Prólogo 3, KSA 2.26) do espírito, que poderá transformar a humanidade, "de moral em sábia" (MA I/HH I 107, KSA 2.105). A luz dessa plena liberdade de quem se livrou do próprio conceito de liberdade (tal como aquela aliada ao livre-arbítrio) e recuperou a inocência, soa mesmo como "o sol de um novo evangelho": "Tudo é necessidade - assim diz o novo conhecimento: e ele próprio é necessidade" (MA I/HH I 107, KSA 2.105). Tudo, pois, é parte da necessidade, inclusive a filosofia nietzschiana - ele não se esquece de destacar esse detalhe que não é um mero acréscimo, posto que esclarece dois pontos importantes: [1] que Nietzsche não vislumbra a sua "verdade" como verdade única e absoluta, mas que a reconhece no jogo das necessidades que caracterizam o conhecimento e a vida; [2] que as interpretações metafísicas que ele denuncia também foram produto da necessidade de outras épocas, mas no sentido de que a fraqueza e a artimanha de seus arautos preferiram, por fraqueza, o consolo e as narcoses, ao enfrentamento saudável dessa condição.

Além disso, não é possível "desprezar esses meios" pelos quais a humanidade chegou até aqui. Falar de uma história é, portanto, falar de um processo cumulativo. Só se pode falar de inocência agora, porque se reconhece essa história, ou seja, porque se dá conta de que "tudo no âmbito da moral veio-a-ser, é mutável, oscilante, tudo está em fluxo" (MA I/HH I 107, KSA 2.105), ou seja, tudo contribui cumulativamente para que a nova luz surja. Eis a importância de uma filosofia histórica, tal como aquela praticada por Nietzsche no texto aqui analisado. $\mathrm{O}$ autor entende que todos os erros anunciados como pretensas verdades foram também produto da necessidade $\mathrm{e}$, portanto, não haveria nada de culpado ou culposo na religião ou na metafísica. Isso foi seu "ser assim", porque "o erro e o descaminho da imaginação foram o único meio pelo qual a humanidade pode gradualmente se erguer até esse grau 
de auto-iluminação e libertação" (MA I/HH I 107, KSA 2.105). Em outras palavras: só é possível falar agora de inocência também como parte desse vir-a-ser. Eis a necessidade que a própria metafísica necessita vislumbrar por debaixo de suas afirmações. E talvez seja o que ela recusa.

Agora, como "tudo é necessidade", o "novo evangelho" anuncia que "tudo é inocência" e que "o conhecimento é a via para compreender essa inocência" como uma "meta" da humanidade (MA I/HH I 107, KSA 2.105). Diante desse novo cenário, a filosofia de Nietzsche, como filosofia das "coisas mais próximas" (WS/AS, 5, KSA 2.541; MA I/HH I Prólogo 5, KSA 2.19) adquire um novo hábito, o hábito do interesse pelas coisas humanas, por aquilo que forma o que é humano - e que inclui os seus erros, as suas falsas interpretações. Um hábito que é, segundo Nietzsche, o de "compreender, não amar, não odiar, abranger com o olhar" (MA I/HH I 107, KSA 2.104) tudo o que está ao redor, tudo o que agora merece atenção e interesse. Um conhecimento que poderá gerar o "homem sábio e inocente (consciente da inocência), da mesma forma regular como hoje produz o homem tolo, injusto, consciente da culpa - que é não o oposto, mas o precursor necessário daquele" (MA I/HH I 107, KSA 2.105). Note-se a confirmação do que afirmamos acima: o homem produzido pela metafísica não é o oposto do novo homem, ao contrário, por entender tudo como parte da história, o procedimento utilizado por Nietzsche faz reconhecer que também o novo homem precisa de um solo, que não há contradição entre o que nasce e o que morre, mas que ambos são complementares, necessários um ao outro. Do contrário, o novo homem seria uma criação também ela des-historicizada e, portanto, metafísica. Compreender isso torna-se uma exigência do método histórico-fisiopsicológico que também é aquele que explicita a exigência de que o homem do passado seja superado para dar lugar ao novo homem, aquele que é homem num sentido diverso, justamente por afirmar sua força no enfrentamento das coisas humanas, a partir de um interesse por elas. 


\section{Para concluir}

Afirmar que "tudo veio-a-ser" como necessidade é liberar o homem para uma nova tábua de valores. Eis a chamada "filosofia da manhã" (MA I/HH I 638, KSA 2.363), aquela da nova luz que ilumina o horizonte da nova humanidade. $\mathrm{Na}$ análise nietzschiana dos ideais religiosos, a denúncia passa pela afirmação de que com eles, o homem também se tornou mais interessante, mais complexo, mais atraente. Ocorre que, como história, todos os sentimentos religiosos e morais também precisam se colocar em movimento, abrir mão das conviç̧ões, sentir o espírito de forma tão "livre e infatigavelmente vivo" para "evitar esse enrijecimento mediante uma contínua mudança" (MA I/HH I 637, KSA 2.362). Avançando "de opinião em opinião", os espíritos livres se desapegaram das grandes convicções para experimentar a liberdade do andarilho ${ }^{14}$, o personagem que fecha o primeiro volume de Humano, demasiado humano, como prenúncio de uma das duas partes do segundo volume, justamente intitulado $O$ andarilho e sua sombra. $\mathrm{O}$ andarilho é o personagem da liberdade plena, daquele que reconhece a falta de meta na existência e que se compraz com a mudança e a passagem. Nietzsche faz da sua, portanto, uma filosofia da viagem, na qual há "alegria na mudança" (MA I/HH I 638, KSA 2.363) mesmo em meio ao sofrimento da verdade, às "noites ruins", ao cansaço e à incompreensão. A viagem é um conceito de tipo antimetafísico. Como tradução metafórica de uma aceitação, a anuência da necessidade de todas as coisas, o andarilho é o personagem da busca, da passagem por várias experiências, da valorização das vivências mais próprias que caracterizam a vida humana, do interesse pelas coisas mundanas, por demais humanas. Ele é o antípoda do proprietário, representado justamente pelo homem da fé, pelos santos

14 Sobre o nomadismo em Nietzsche, cf. MIRABLE, 2004, p. 237-277, no qual se apresenta o pensamento nietzschiano como um pensamento nômade. 
e ascetas, muitos dos quais, aliás, também foram andarilhos, mas não conseguiram se desvencilhar de seus próprios ideais. Viajaram sem sair de casa. Permaneceram aprisionados pelas cadeias metafísicas.

Por fim, precisamos reconhecer como Humano, demasiado humano não só representa um momento de extrema importância na filosofia de Nietzsche no que tange ao rompimento com as ideias metafísicas e com os projetos confessados por ele nos seus escritos anteriores, como também um prenúncio da grande liberdade usufruída pelo filósofo alemão em seus escritos posteriores, principalmente quanto a muitos dos conceitos de sua filosofia tardia, os quais se acham embrionários na obra de 1878. Nela Nietzsche renova as ferramentas de sua filosofia e muda as equipagens com as quais viajará de ora em diante.

\begin{abstract}
We intend to analyze, in this article, the Nietzsche's historical-physio-psychological strategy in Human, All Too Human, in regard to his analysis of religious metaphysics and, more specifically, of asceticism. For this, we'll try to demonstrate how the Nietzschean argument gets to the theory of innocence of the human being and the demonstration that asceticism and holiness would remain as an exercise of power of the individual over himself, as dominating impulses, tyrannizing over some portions of their own nature that, with the absence of external "objects" finishes turning against itself, resulting in the contempt and scorn of man to himself, feeling that leads to the morality of guilt. The procedure of Nietzsche, to alleviate man of that weight, would restore the innocence and irresponsibility by way of affirmation of the need of all things and critique the idea of free will.
\end{abstract}

Keywords: religion - Human - Innocence - asceticism

\title{
referências bibliográficas
}

1. ABBEY, R. Nietzsche’s middle period. Oxford: Oxford University Press, 2000.

242 I Cad. Nietzsche, São Paulo, n. 33, p. 215-244, 2013. 
2. D'IORIO, P. Le Voyage de Nietzsche à Sorrento. Genèse de la philosophie de l'esprit libre. Paris: CNRS éditions, 2012.

3. GIACÓIA JR., O. Nietzsche como psicólogo. São Leopoldo: Editora Unisinos, 2006. (Col. Focus, 6).

4. ITAPARICA, A. L. M. Nietzsche e o sentido histórico. In: Cadernos Nietzsche, 19, São Paulo, 2005, p. 79-99.

5. N Notas sobre a naturalização da moral em Nietzsche. In: PASCHOAL, Antonio Edmilson; FREZZATTI JR., Wilson Antonio (orgs). 120 anos de Para a Genealogia da Moral. Ijuí: Editora Unijuí, 2008, p. 29-46.

6. MIRABILE, P. The nomadic thought Friedrich Nietzsche and Zhuang Zi: convergences and divergences. Nietzsche Studien, 33, Berlin: Walter de Gruyter Inc., 2004, p. $237-277$.

7. NIETZCHE, F. Aurora. Trad. de Paulo César de Souza. São Paulo: Cia. das Letras, 2004.

8. _ Humano, Demasiado HumanoTrad. de Paulo César de Souza. São Paulo: Cia. das Letras, 2000 (Vol. I) e 2008 (Vol. II).

9. S_ Sämtliche Briefe. Kritische Studienausgabe (KSB). Herausgegeben von Giorgio Colli und Mazzino Montinari. München/Berlin/New York: dtv/Walter de Gruyter \& Co., 1986. (8 Bänden).

10. Sämtliche Werke. Kritische Studienausgabe (KSA). Herausgegeben von Giorgio Colli und Mazzino Montinari. München/Berlin/New York: dtv/Walter de Gruyter \& Co., 1988, 15 v.

11. OLIVEIRA, J. R. de. A psicologia como procedimento de análise da moralidade nos escritos intermediários de Friedrich Nietzsche. Estud. pesqui. psicol., Rio de Janeiro, v. 9, n. 3, dez. 2009, p. 560-581. Disponível em: http://goo.gl/7DYpt. Acesso em: 12 abr. 2013.

12. Nietzsche e a falha do espelho ou sobre como interpretar também é inocentar. In: AZEREDO, V.D. de; SILVA J., I. (org.). Nietzsche e a interpretação. Curitiba: CRV; São Paulo: Humanitas, 2012. (Col. Nietzsche em Perspectiva, 1), p. 237-246.

13. PONTON, O. Nietzsche - Philosophie de la lègèreté. Berlin; New York: Walter de Gruyter, 2007. (Monographien und Texte zur Nietzsche-Forschung, Band 53).

14. RAMACCIOTTI, B. Nietzsche: fisiologia como fio condutor. Revista Estudos Nietzsche, v. 3, n. 1, p. 65-90, jan./jun. 2012.

15. RÉE, P. Basic Writings. Translated and edited by Robin Small. Chicago: University of Illinois Press, 2003.

16. SMALL, R. Nietzsche and Rée. A star friendship. New York: Oxford University Press, 2009.

Cad. Nietzsche, São Paulo, n. 33, p. 215-244, 2013. | $24 \mathbf{3}$ 
Oliveira, J. R.

17. TONGEREN, P. v. A moral da crítica de Nietzsche à moral: estudo sobre "Para além de bem e mal". Trad. Jorge Luiz Viesenteiner. Curitiba: Champagnat, 2012.

18. WOTLING, P. La philosophie de l'esprit livre. Paris: Éditions Flammarion, 2008.

Artigo recebido em 11/05/2013.

Artigo aceito para publicação em 22/06/2013.

244 | Cad. Nietzsche, São Paulo, n. 33, p. 215-244, 2013. 